D.G. Koliushko, S.S. Rudenko

\title{
A COMPUTER PROGRAM FOR INTERPRETATION OF THE DATA OF VERTICAL ELECTRICAL SOUNDING VEZ-4A
}

Purpose. Creating a computer program for interpreting the results of vertical sounding the soil in the form of multilayer model most typical for Ukraine. Methodology. The algorithm of the program is constructed on determination the soil structure with the help of the method of point source current, method of analogy and method of equivalent. The option of automatic interpretation based on Hook-Jeeves method. The program is implemented in the programming language Delphi. Results. The computer program "VEZ-4A" has a possibility of the interactive and automatic interpretation sounding results in the multi-layered geoelectrical model. Originality. In first time the computer program for analyzing and interpreting results of the soil sounding by Wenner configuration was created on the base of the analytical solution for field of current point source located in four-, threeor two-layer structure. In paper the review is presented and basic functions of our program are analyzed. Practical value. The program "VEZ-4A» is created and adapted for use in the electromagnetic diagnostics of grounding of existing power plants and substations. References 7, tables 1 , figures 3.

Key words: vertical electrical sounding, grounding, soil, Wenner installation.

В работе был предложен алгоритм работы программы для интерпретации результатов вертикального электрического зондировании грунта в рамках диагностики состояния заземляющих устройств. Математический аппарат для реализации алгоритма построен на базе методов точечного источника тока, наименьщих квадратов, Хука-Дживса и эквивалентирования. Приведено описание и основные функции разработанной программы. Библ. 7 , табл. 1 , рис. 3.

Ключевые слова: вертикальное электрическое зондирование, заземление, грунт, установка Веннера.

Introduction. One of the main objectives of the first phase of the electromagnetic diagnostics of grounding device $[1,2]$ of electrical voltages of different classes is vertical electric sounding (VES) of soil. The quality of the interpretation of results of VES and definition of the soil structure greatly affect the accuracy of the calculation of normalized electrical parameters: resistance of the grounding device, touch voltage and voltage on the grounding device.

Currently a number of specialized software for $1 \mathrm{D}$, $2 \mathrm{D}$ and $3 \mathrm{D}$ interpretation of VES are known. The basis for the method of their construction is Dar Zarruk [3] method or analytical method based on optical analogy to solve the problem of the electric field of a point power source located on the surface of the geoelectric structure. Here, this source of constant, stationary or quasistationary current is considered $[4,5]$. However, mathematical tools and specialized programs that define the structure of multilayer soil based on VES data, serve to resolve narrow-geological problems and is not adapted for use in the diagnosis of grounding systems and the use of existing universal pallets and method modules are expensive and ambiguous [ 6]. In the frame of the electromagnetic diagnosis of grounding devices state programs are used to interpret the VES as two- and three-layer geoelectric structures, such as «VEZ-2Auto» and «VEZ-3», which do not allow to cover all existing in Ukraine soils.

The statistical distribution of soils according to the number of layers in the locations of power Ukraine shows that the vast majority of soils have a three-layer structure $-72.7 \%$, about $17 \%$ is four-layer and only $8.3 \%$ - twolayer [2]. Thus, development of the software to interpret the results of the VES with number of layers at least four will cover $98 \%$ of soils in Ukraine in the placements of power objects.

The goal of the work is development of a software for interpreting the results of the vertical electrical sounding of the four-layer soil.

Materials of investigations. The most common for VES is the Wenner installation, which is a four-electrode symmetrical system (Fig. 1). Interelectrode distance is equal between all neighboring electrodes also affects the size $L$. Probing depth is half the distance between the current electrodes AB or 1.5.L [3]. Thus, increasing the interelectrode distance increases the depth of sensing by the installation.

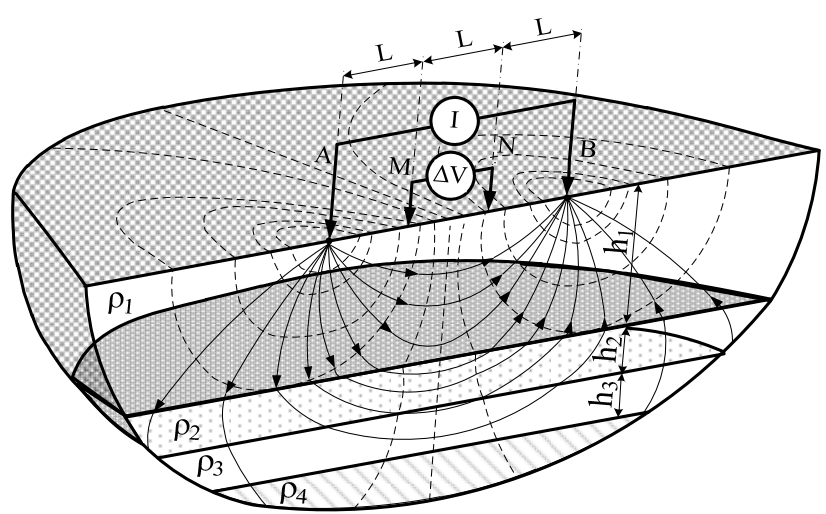

Fig. 1. Soil sounding by using the Wenner installation

The result of measurement is the dependence of imaginary specific electrical resistance (SER) $\rho_{y}$ on the interelectrode distance, determined by the known expression $[4,7]$

$$
\rho_{y}=2 \pi L \frac{U_{V E S}}{I_{V E S}},
$$

where $L$ is the distance between electrodes; $U_{V E S}$ is the voltage measured during VES; $I_{V E S}$ is the current measured during VES.

For the interpretation as the basis of program the embedded expressions for imaginary SER $\rho_{y}$ is used as a function of the value $L$ in multilayer medium with planeparallel outside the division during VES by using the Wenner installation:

- at the two-layer structure [7]:

$$
\rho_{y}=\rho_{1}\left\{1+4 \sum_{n=1}^{\infty} K_{2,1} n\left[\frac{L}{\sqrt{L^{2}+(2 n h)^{2}}}-\frac{L}{\sqrt{4 L^{2}+(2 n h)^{2}}}\right]\right\}
$$


where $h$ is the depth of the layer division in the two-layer model and the common measure in the three-layer model; $K_{2,1}=\left(\rho_{2}-\rho_{1}\right) /\left(\rho_{2}+\rho_{1}\right)$ is the heterogeneity rate; $n$ is the number of the member of the series; $L$ is the distance between nearest electrodes;

- at the three-layer structure:

$$
\rho_{y}=\rho_{1}\left\{1+4 \sum_{n=1}^{\infty} q_{n}^{n}\left[\frac{L}{\sqrt{L^{2}+(2 n h)^{2}}}-\frac{L}{\sqrt{4 L^{2}+(2 n h)^{2}}}\right]\right\},
$$

where $q_{n}$ is the coefficient of expansion of the integrand function [4].

Formulas (2) and (3) are obtained by using the expression for the electric field potential of the point source current in multilayer environment [4], at the placement of it and the observation point on the ground surface. In this case, (3) was obtained using the method of undetermined coefficients.

In the frame of improving the method of electromagnetic diagnosis of the grounding device based on the analytical solution of the problem of the electric field of a point power source located on the surface of the four-layer conducting half-space with plane-parallel boundaries of division, the authors have developed mathematical apparatus [5] for the interpretation of results of sounding and equivalentiation [2] of multilayer structures in the computational models.

To enable the software development, the authors used the earlier solution [5] of the stated the problem, provided the location of the observation point on the surface of the four-layer soil. In that case, the imaginary SER will look like:

$$
\begin{aligned}
& \rho_{y}=\rho_{1}+\rho_{1} \sum_{j=1}^{3}\left(4 K _ { j + 1 , j } \cdot \sum _ { n = 0 } ^ { k _ { u r } } \left[\frac{K_{n} L}{\sqrt{L^{2}+\left(2 h_{j}+2 n\right)^{2}}}-\right.\right. \\
& \left.\left.-\frac{K_{n} L}{\sqrt{4 L^{2}+\left(2 h_{j}+2 n\right)^{2}}}\right]\right),
\end{aligned}
$$

where $K_{j+1, j}$ is the heterogeneity rate determined as $K_{j+1, j}=\frac{\rho_{j+1}-\rho_{j}}{\rho_{j+1}+\rho_{j}} ; K_{n}$ is the factors obtained as a resilt of the expansion of the function characterizing the multilayer medium; $n$ is the number of the member of the series; $k_{u r}$ is the total number of the members of the series.

A function characterizing the multilayer medium has a form [5]:

$$
F_{Z}^{\prime}(\lambda)=\frac{1}{F_{Z}(\lambda)}
$$

where $F_{Z}(\lambda)$ is determined as follows:

$$
\begin{aligned}
& F_{Z}(\lambda)=1-K_{2,1} e^{-2 \lambda h_{1}}-K_{3,2} e^{-2 \lambda h_{2}}-K_{4,3} e^{-2 \lambda h_{3}}+ \\
& +K_{2,1} K_{3,2} e^{-2 \lambda\left(h_{2}-h_{1}\right)}+K_{2,1} K_{4,3} e^{-2 \lambda\left(h_{3}-h_{1}\right)}+ \\
& +K_{3,2} K_{4,3} e^{-2 \lambda\left(h_{3}-h_{2}\right)}-K_{2,1} K_{3,2} K_{4,3} e^{-2 \lambda\left(h_{3}-h_{2}-h_{1}\right)} .
\end{aligned}
$$

The value of $K_{n}$ from the expression (4) is founded at the solution by the method of least squares of the system of equations, developed for the function approximation characterizing the multilayer medium (5), by the method given in [5], taking into account the number of layers of soil and $h_{n}=2 \cdot n$.

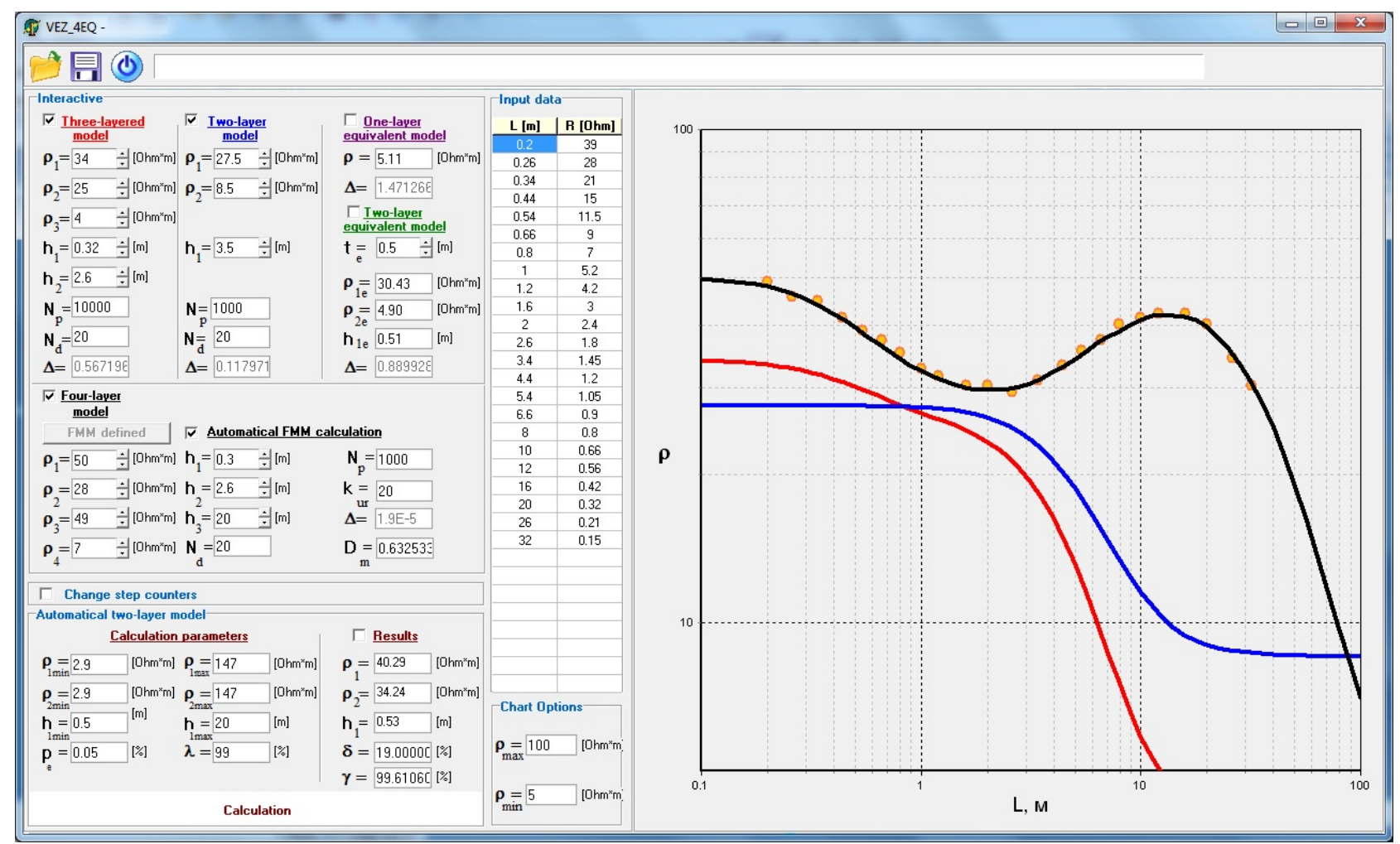

Fig. 2. A working window of the software for multi-layer soils interpretation «VEZ-4A»

Based on expressions (1) - (4) and using the method of least squares for the approximation of the function that characterizes the multilayer soil, in the software environment Delphi developed has developed a program 
for interpreting the results of VES as four-layer geoelectric structure «VEZ-4A», which interface is shown in Fig. 2.

The developed program permits to perform both interactive and automatic interpretation of VES results.

When approximating functions characterizing multilayer medium we should consider the change of the interval of the dimensionless parameter $\lambda \in[0 ; \infty]$. The required number of members of series $k_{u r}$ is determined by the relative error of approximation $D_{m}$ of the output function (5), recommend value of it (see Fig. 2) is not more than $1 \%$. Here, $F_{Z}^{\prime}(\lambda)=1$ at $\lambda \rightarrow \infty$.

The feature of the program is that in addition to the standard algorithm also contains the following blocks (see Fig. 3):

- automatic interpretation block in the form of a twolayer model Block 1;

- interactive interpretation block in the form of a twolayer model Block 2;

- interactive interpretation block in a three-layer model Block 3;

- interactive interpretation block as a four-layer model Block 4.

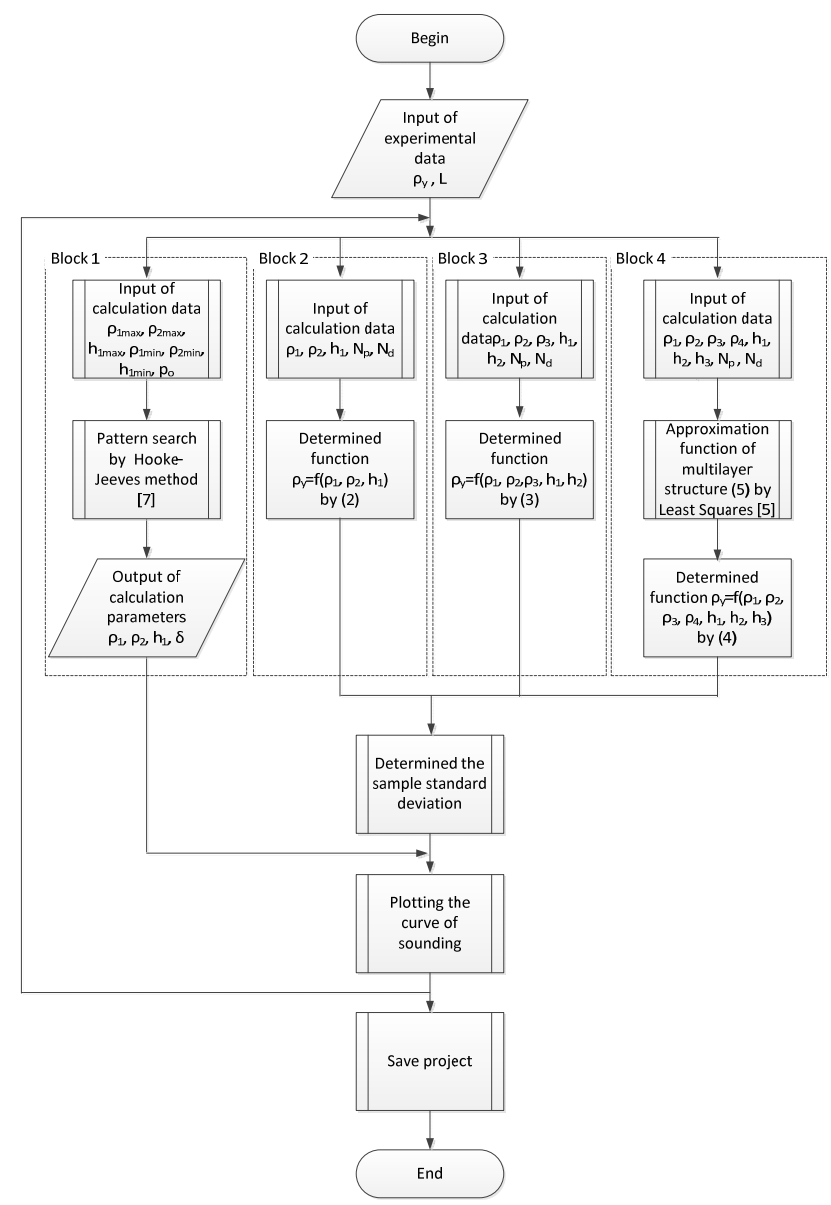

Fig. 3. An algorithm of the software operation

The standard blocks include the following:

- Input of experimental data $\rho_{y}, L$;

- Determined the sample standard deviation;

- Plotting the curve of sounding;

- Save project.
Methods and expressions for the block of equivalentiation (not specified in the algorithm) that were used in the program are given in [2].

Start of calculation and graphical display of VES takes place when selecting the appropriate models (Block 1 - Block 4).

By varying parameters of the models - SER of layers and their thicknesses - the largest compliance of the VES curve with experiment is reached. Here, the control of compliance is carried out in two ways:

1) by visual comparison of experimental points and calculated VES curve on the graph;

2) by analysis of the value of the standard medium deviation $\Delta$ (its lowest value corresponds to the maximum precision).

Change the settings of models is also possible in two ways:

1) direct input of the parameter value to the field;

2) to change by the step by step method using the the component of Delphi «UpDown».

Step of the specified component is floating and depends on the absolute value of the parameter.

For automatic interpretation of the results of VES in the block «Automatic calculation of two-layer model» in the «Calculation options» we have to set limiting parameters of the search (at the beginning they are automatically set according to the minimum and maximum values of the experimental VES curve, in the future they can be changed by the user), the probability of errors $p_{e}$ (default value 0.05 ) and reliability of the calculation $\lambda$ (default value $99 \%$ ). It should be noted that with decreasing $p_{e}$ and increasing $\lambda$ the calculation time will increase.

Start of the procedure occurs when you click «Calculation» button or «Space» on the keyboard, and graphical display of the VES curve - when selecting the corresponding component «CheckBox» for each model of soil.

In the block «Results» the software displays obtained values of model parameters calculation $\left(\rho_{1}, \rho_{2}\right.$ and $h_{1}$ ), and maximum deviation of calculation results from the experimental data $\delta$ and the reliability of the model $\gamma$ (accepted values of these parameters are selected under the terms of the problem solved, recommended values are $\delta \leq 10 \%$ and $\gamma \leq 95 \%$ ). If you obtained too much value of $\delta$ or low $\gamma$, then the options to improve the accuracy of calculation are:

- to increase limiting values of the search parameters in the section «Calculation options»;

- reducing the probability of error $p_{e}$ and (or) to increase the reliability of the calculation $\lambda$;

- to delete clearly erroneous error point from the block «Initial data» if it does not meet the trends of placement of the experimental VES curve.

\section{Conclusions.}

1. The authors developed the algorithm of the software operation the feature of it is the possibility of interpreting the VES results interactively or automatically as two-, three- and four-layer soil.

2. The program is implemented for interpretation of the VES results based on a mathematical model to determine 
the potential of the electric field of a point current source located in a four-layer half-space.

3. The developed program «VEZ-4A» can cover about $98 \%$ of soils in the locations of energy facilities in Ukraine.

The program for interpreting the results of the VES has been successfully used in the conducting electromagnetic diagnosis of grounding systems state for 10 substation of the voltage class of $150 \mathrm{kV}$, 20 substations of the voltage class $110 \mathrm{kV}$ and substation ВРП-750 kV of the Rivne NPP in 2015-2016.

\section{REFERENCES}

1. Natsional'nyy standart Ukrayiny. SOU 31.2-2167768119:2009. Viprobuvannya ta kontrol' prystroyiv zazemlennya elektroustanovok. Tipova instruktsiya. [National Standard of Ukraine SOU 31.2-21677681-19:2009. Test and control devices, electrical grounding. Standard instruction]. Kyiv, Minenergovugillya Ukrayiny Publ., 2010. 54 p. (Ukr).

2. Koliushko D.G., Rudenko S.S., Koliushko G.M. Analysis of electrophysical characteristics of grounds in the vicinity electrical substation of Ukraine. Electrical engineering \& electromechanics, 2015, no.3, pp. 67-72. (Rus). doi: 10.20998/2074-272X.2015.3.10.

3. Shevnin V.A., Kolesnikov W.P. Rating depth VES for the uniform and layered medium. Electronic Journal «GEORazrez», 2011, no.1(8), pp. 1-9. Available at: http://www.georazrez.ru/download/2011/08/Shevnin-

Otcenka_glubinnosti_VEZ.pdf(Accessed 10 November 2013). (Rus).
4. Burgsdorf V.V., Yakobs A.I. Zazemlyayushchie ustroystva elektroustanovok [Grounding device of electrical installations]. Moscow, Energoatomizdat Publ., 1987. 400 p. (Rus).

5. Koliushko D.G., Rudenko S.S. Interpretation the results of the vertical electrical sounding as the geoelectrical half space with four layer. Bulletin of NTU «KhPI», 2015, no.12(1121), pp. 324-329. (Rus).

6. Koliushko G.M., Koliushko D.G., Rudenko S.S. On the problem of increasing computation accuracy for rated parameters of active electrical installation ground grids. Electrical engineering \& electromechanics, 2014, no.4, pp. $65-$ 70. (Rus). doi: 10.20998/2074-272X.2014.4.13.

7. Petkov A.A., Koliushko D.G., Link I.Y. Determination of parameters two-layer model of ground on the results for the vertical electric sounding conducted in the vicinity of substation. Electrification and automation of agriculture, 2004, no.2(7), pp. 3-11. (Ukr).

Received 06.04.2017

D.G. Koliushko ${ }^{1}$, Candidate of Technical Science, Senior Research Associate

S.S. Rudenko ${ }^{1}$, Research Associate,

${ }^{1}$ National Technical University «Kharkiv Polytechnic Institute», 2, Kyrpychova Str., Kharkiv, 61002, Ukraine,

e-mail:nio5_molniya@ukr.net

\section{How to cite this article:}

Koliushko D.G., Rudenko S.S. A computer program for interpretation of the data of vertical electrical sounding VEZ-4A. Electrical engineering \& electromechanics, 2017, no.3, pp. 63-66. doi: 10.20998/2074-272X.2017.3.09. 